\title{
PARCEL DELIVERY IN AN URBAN ENVIRONMENT USING UNMANNED AERIAL SYSTEMS: A VISION PAPER
}

\author{
B. Anbaroğlu \\ Dept. of Geomatics Engineering, Hacettepe University, Ankara, Turkey - banbar@ hacettepe.edu.tr
}

KEY WORDS: Unmanned Aerial Systems (UAS), drones, logistics, parcel delivery

\begin{abstract}
:
This vision paper addresses the challenges and explores the avenue of solutions regarding the use of Unmanned Aerial Systems (UAS) for transporting parcels in urban areas. We have already witnessed companies' delivering parcels using UAS in rural areas, but the challenge of utilizing them for an urban environment is eminent. Nevertheless, the increasing research on the various aspects of UAS, including their battery life, resistance to harsh weather conditions and sensing its environment foresee their common usage in the logistics industry, especially in an urban environment. In addition, the increasing trend on 3D city modelling offer new directions regarding realistic as well as light 3D city models that are easy to modify and distribute. Utilizing UAS for transporting parcels in an urban environment would be a disruptive technological achievement as our roads will be less congested which would lead to less air pollution as well as wasted money and time. In addition, parcels could potentially be delivered much faster. This paper argues, with the support of the state-of-the-art research, that UASs will be used for transporting parcels in an urban environment in the coming decades.
\end{abstract}

\section{INTRODUCTION}

The logistics sector is one of the key sectors in today's world having close ties with spatial information science as parcels are transported from one location to another. Various types of parcels are transferred ranging from letters to chemicals, some of which had to be kept at certain temperatures and should be kept still during the transportation. Consequently, various forms of logistics exist, but the wide usage of e-commerce leads to the fact that the majority of urban logistics comprise of parcels that are transferred between businesses to businesses or customers in an urban environment (Lindholm, 2013).

There are several important issues that logistics industry is facing in an urban environment. First, local carriers usually use old vehicles that emit large amounts of pollutants in order to reduce the increasing costs. For instance, in Paris the trucks that serve as the medium of logistics companies cause $15-20 \%$ of vehicle congestion and nearly $60 \%$ of particle emissions (Dablanc et al., 2011). Second, researchers have identified that logistics companies may not operate efficiently leading to a higher than optimal vehicle-kilometers due to ineffective planning (Jiang and Mahmassani, 2014). In addition to not effectively incorporating the temporal dimension whilst route planning (Nha et al., 2012), finding parking spaces in already congested urban environments also contribute to this inefficiency (Jean-Marie Boussier et al., 2011). Third, in today's mobile world, businesses or customers often require express or urgent deliveries; hence, forcing the logistics companies to be more flexible as well as provide just-in-time delivery.

The proliferation of Unmanned Aerial Systems (UAS) for civil markets would have an added value both in terms of economy as well as job creation. The economic impact of the integration of UAS is estimated to add more than $\$ 13.6$ billion in its first three years and will grow to $\$ 82.1$ billion in the next 10 years. In addition, the emergence of utilizing UAS for civil markets is estimated to create 34000 manufacturing jobs and more than 70000 new jobs in the first three years of the integration (Jenkins and Vasigh, 2013). The main reason for this prospect is that UAS can perform tasks similar to those that can be done by manned vehicles but often faster, safer, and at a lower economic and environmental cost.

This paper provides a vision towards the utilization of UAS (or drones) in the logistics industry, specifically delivering of parcels in an urban environment. The second section provides the related work, and third section provides the vision towards the delivery of parcels in an urban environment using UAS. The last section is the conclusion.

\section{RELATED WORK}

The research agenda on UAS have started, as with most of the other technological advancements, through military needs. However, the prospects of deploying UAS have attracted many other domains including, but not limited to, photogrammetry and surveying (Colomina and Molina, 2014), agriculture (Yang et al., 2016), environmental monitoring ( $\mathrm{Ni}$ et al., 2017), entertainment (Quiroz and Kim, 2017), forestry (Casbeer et al., 2005), construction surveillance (Javier Irizarry and Dayana Bastos Costa, 2016), infrastructure protection (Gómez and Green, 2017) and rescue operations (Efrat et al., 2012). These various application domains, coupled with the increasing $R \& D$ activities regarding UAS leads to a positive loop of productivity.

Those research areas which had already demonstrated the applicability of UAS; however, are limited to research and the wide usage of UAS for any civilian domain has still not been realized. This is because there are three facades of UAS: i) public acceptance, ii) regulations, and iii) technology; often in relation with each other as illustrated in Figure 1 (Heutger and Kückelhaus, 2014). However, progress has been achieved in all these, sometimes conflicting, facades. Now, companies and legal bodies are working towards the realization of wide usage of UAS in a civilian context.

Public acceptance is one of the facades of using UAS at a large scale; since citizens have safety and privacy concerns. 
Researchers consider that the appearance, routing, level of autonomy affect the citizens' view towards UAS. For example, whereas laypeople fear the violation of their privacy, active UAS pilots consider more of a risk in possible accidents (Lidynia et al., 2017). Therefore, it is important to inform citizens beforehand regarding the routes of UAS. Another public concern is due to the security of these systems. UAS controlled by WiFi use IEEE 802.11 standards, which is vulnerable to security breaches (Vattapparamban et al., 2016). The outcome of a recent research suggests that, although the commercial use of UAS can improve lifestyle and increase efficiency, there is a need to invest more attention to convince the citizens (Luppicini and So, 2016). Even though most people would enjoy the improved lifestyle offered by technology, there should be clear and concise guidelines addressing the public concerns on the wide usage of UAS.

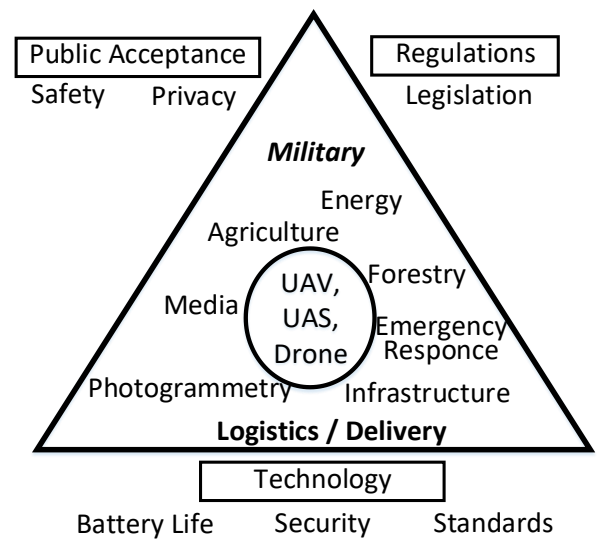

Figure 1 Three Facades of UAS

The legal bodies such as Federal Aviation Administration (FAA) of US or Civil Aviation Authority (CAA) of the UK are working towards providing the regulations of flying UAS for commercial purposes. For instance, FAA, amongst other, requires that UAVs must have onboard "detect, (sense) and avoid" capabilities (Shively, 2014). In addition, they classify UAS -therefore the relevant regulations- based on their takeoff weight (Oliver, 2017). On the other hand, CAA "requires drone flights to stay away from persons not actually involved in the flight operation and to be at least 150 metres from structures" which prevent the mass use of UAS for logistics in an urban environment (Harrington, 2015). Consequently, at the moment, the regulations in developed countries do not allow the mass use of UAS for civilian use. Nevertheless, it is safe to state that these regulations are subject to change depending on the progress in science and technology.

There is an increasing coverage with respect to UAS both in the media or scholarly databases indicating the positive trend for their common use. In one of the main scholarly databases, SCOPUS, the number of papers including the terms "unmanned aerial systems", "unmanned aerial vehicles" and "drones" (it should be noted that "drone" also refers to a male bee; hence, the results are overestimated) is searched and the total number of papers for each year is denoted with "UAS" in Figure 2. More than five thousand papers had been published in 2016, which almost doubled the previous year's record. Similarly, the term "logistics" is added to these three terms and the total number of papers for this search is denoted with "UAS + Logistics". Even though the "logistics" account for about $1 \%$ of the total publications within the broad area of UAS, the involvement of big companies including Amazon, DHL, and JD (one of the biggest online retailers in China) and Google foresee that there would be an increasing research for UAS monitoring and management systems (Itkin et al., 2016). Therefore, it is not surprising to hear NASA's senior engineer for air transportation systems stating that "we need to accommodate drones" in air traffic control systems (Schneider, 2017).

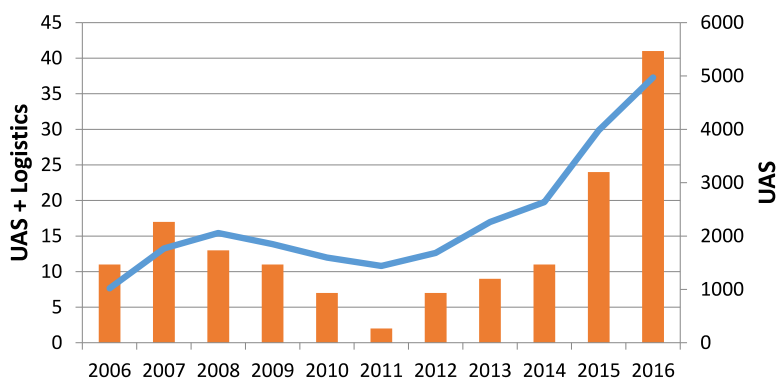

UAS + Logistics UAS

Figure 2 Total number of articles including the terms UAS and Logistics

Delivering, especially medical, products using UAS has already been researched. For instance, researchers have simulated that it would be economically viable to transport vaccines using UAS if they are used frequently enough to overcome the capital costs (Haidari et al., 2016). In addition to the economic viability, such a scenario has also proven to improve supply chain performance since higher vaccine availability would be provided to those living on rough terrains. Researchers have also identified the necessity of relying on UAS especially in disaster relief scenarios where roads are damaged or cannot be effectively used to provide medical relief, also known as "humanitarian logistics" (Chowdhury et al., 2017; Fikar et al., 2016). As different situations have different requirements, researchers have investigated numerical analysis to determine the tradeoffs between using faster speeds versus longer endurance of UAS (Murray and Chu, 2015). Even though the problems associated with delivering parcels in an urban environment, such as noise emission, security and safety risks and local ecologic impacts are known (Kunze, 2016); the advancements in science and technology could potentially provide solutions to these issues.

The progress in other aspects of UAS would also add further support with respect to their usage for logistics. Currently, most of the small UASs are powered by lithium-ion or lithium polymer batteries and their flight endurance is limited to a few hours. Consequently, prolonging the battery life of UAS is one of the key research agendas, and methods like wireless charging (Choi et al., 2016), developing effective UAS designs (Larsen et al., 2017) and investigating the use of fuel-cells (Kim et al., 2011) contribute to this agenda. Another prominent research area in geographical information science having close ties with research on UAS is the 3D urban modelling (Biljecki et al., 2015). Open standards like Geographic Markup Language (GML) and its specialized version CityGML offer the means to develop and distribute such 3D city models (Belussi et al., 2015; Gröger and Plümer, 2012). However, there are still open research issues including the utilization of accurate elevation data (Biljecki et al., 2017) and how these models could effectively be incorporated in an UAS.

\section{UTILIZATION OF UAS FOR LOGISTICS}

In an urban environment delivery of parcels using UASs would be achieved through three main steps: i) dispatch, ii) shipment 
and iii) delivery. During dispatch the parcel to be delivered is removed from the repository to be sent to the customer. Shipment is the transportation of the parcel to the customer and delivery occurs when the parcel is delivered to its destination as depicted in Figure 3. Here, the UAS is assumed to have the capability of Vertical Take-Off and Land (VTOL) due to their ease of use in an urban environment. Last, autonomy, in all three aspects of the process, is desired in order to provide a faster and probably secure delivery.

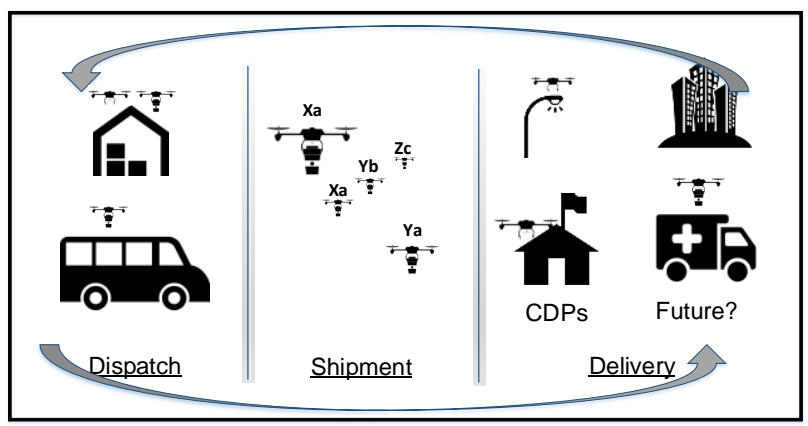

Figure 3 Parcel delivery using UASs in an urban environment

During dispatch the relevant parcel is loaded to an UAS with the address of the customer. There might be new UAS where more than once parcel could loaded to serve more than one customer in a single launch. The dispatch could occur through a stationary repository or a vehicle. Repositories could hold more parcels and UAS; however, they might not be well spatially distributed to cover an entire urban environment leading to some areas being uncovered. In that case mobile repositories could be utilized containing several UAS to serve more than one customer at a time; hence, still improving today's state-of-thepractice. Nevertheless, mobile repositories might even not be needed in the likely progress of UAS having longer trip distances and battery life. Dispatch is mostly related to a single company's operation. However, there would be several logistics companies delivering parcels in an urban environment.

Shipment process, therefore, requires the technology guided by well-defined regulations and standards so that the security of UASs sharing the same aerial resources is guaranteed. In addition, there would probably be different UAS models in operation. For instance, in the Figure 3, the companies " $X$ " and " $Z$ " has the single UAS model "a" and "c" respectively; whereas company "Y" has two types of UAS models; "a" and "b". Different companies using different UAS models to ship parcels would require aviation agencies to have strict and clear requirements. First, there should be air corridors, just like for aircrafts to have a better management of the UAS flocks (Feng and Yuan, 2016). These air corridors would be defined by the agencies and followed by the companies. The increasing research efforts on modeling flocks of UASs in order to prevent collision between each other add further support to the realization of this requirement (Leonard et al., 2012; SanchezLopez et al., 2017). In addition, monitoring such a large scale trajectory data would necessitate aviation agencies to rely on the state-of-the-art spatial analytics methods (Tahboub and Rompf, 2016). Second, UAS should be aware of its surrounding and take decisions accordingly in real-time. In other words, it should well sense its environment in order to avoid unexpected crashes with natural and/or man-build structures (Muñoz et al., 2015). Third, issues regarding the localization of an UAS should be addressed and precise location of an UAS should be obtained at all times in an urban environment. The high-rise buildings might block the GPS signals leading to the "urban canyon problem" or GPS signals could get reflected by different objects including buildings or the ground. However, recent researches indicate that positional accuracies as low as an average of 0.36 meters could be reached allowing us to detect the lanes in which a vehicle is travelling (Zabihi et al., 2015). Last, progress in machine vision and deep learning provide solutions so that UAS can navigate through GPS-denied environments (Pestana et al., 2013; Smolyanskiy et al., 2017).

Finally, the parcel should be delivered. The most plausible scenario for delivery is to rely on "Collect and Delivery Points" (CDPs), where customers can pick up their parcel. These stationary locations are believed to be the best way to solve urban end-distribution problems (Jesse W.J. Weltevreden, 2008). There are two main types of CDPs: i) attended and ii) non-attended. In attended CDPs an officer is employed whom the customer interacts, whereas in non-attended CDPs customers use some sort of identification (e.g. PIN number) to pick up their parcel. The parcels could be delivered to both types of CDPs. Indeed, Amazon has already issued a patent application to use lamp posts as a CDP, which could also be used to recharge UASs, adding further support to the realization of this concept (Coulton et al., 2017). Apart from having a more organized way of delivery, relying on CDPs would also have the advantage of delegating the recognition of the customer to CDPs. Once the technology to deliver parcels to CDPs is established, the next leap would be towards delivering parcels (especially food deliveries which are quite common in the UK which is expected to reach $£ 200$ billion in 2019 (Zissis et al., 2017)) to residential buildings or even moving emergency vehicles in an urban road network.

There are many challenges to utilize UAS for parcel delivery in an urban environment, but there is a growing amount of research to overcome these challenges. The challenges are classified under three categories: i) societal, ii) public authorities and iii) technological. Some of the challenges are intertwined (e.g. the manoeuvres that an UAS should take to "sense \& avoid" would directly affect its battery life). Nevertheless, Table 1 provides an overview to these challenges and explores the avenue of solutions for each challenge. 


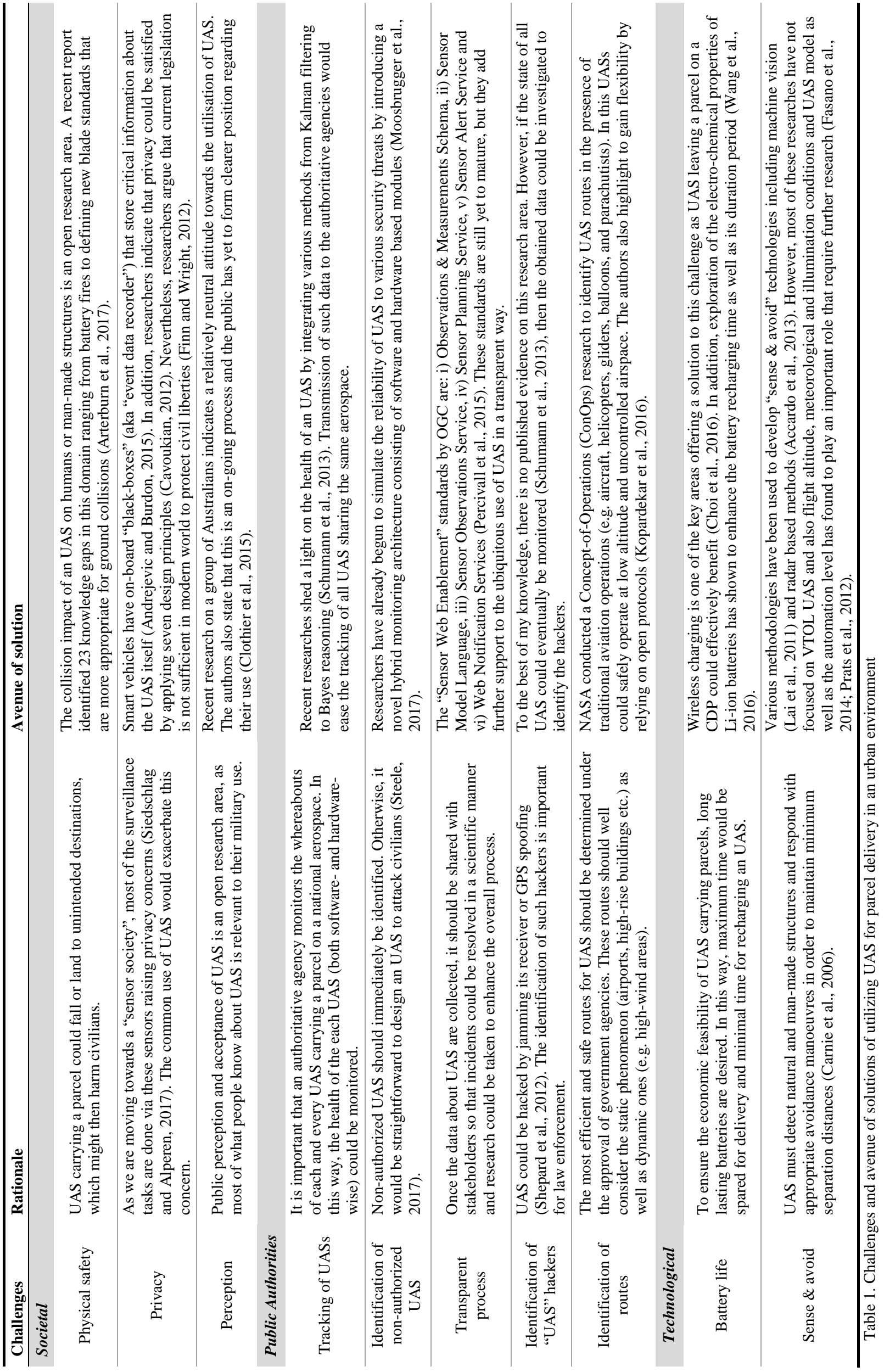




\section{CONCLUSION}

Most of the societal changes, especially those backed up by technological advancements; might initially seem to be frightening or improbable. Yet, they would eventually get realized due to economic necessities. Even though there is a substantial R\&D activity in the broad area of UAS, we still have not yet experienced their wide usage in a civilian context. This paper envisions that the first wide usage of UAS for civilian purposes would be in the area of logistics, specifically delivery of parcels in an urban environment. This is because regardless of our differences including age, gender, citizenship or occupation; we rely on some "things" to be delivered. Whether a doctor waiting for a medicine or a teenager waiting for a meal; we all expect some "one" will deliver what we seek for. Consequently, using UAS to deliver parcels would have the largest societal impact. The very recent purchase of Whole Foods by Amazon also signal the fact that e-commerce would revolutionize in the coming years. Considering that the technological advancement is almost there and that the societal acceptance and legislation to follow up; there is no reason preventing the fact that we will be seeing hundreds of UAS carrying our parcels in the coming decades.

\section{REFERENCES}

Accardo, D., Fasano, G., Forlenza, L., Moccia, A., Rispoli, A., 2013. Flight test of a radar-based tracking system for UAS sense and avoid. IEEE Trans. Aerosp. Electron. Syst. 49, 11391160 .

Andrejevic, M., Burdon, M., 2015. Defining the Sensor Society. Telev. New Media 16, 19-36.

Arterburn, D., Ewing, M., Prabhu, R., Zhu, F., 2017. FAA UAS Center of Excellence Task A4: UAS Ground Collision Severity Evaluation, Final Report. University of Missisipi.

Belussi, A., Migliorini, S., Negri, M., Pelagatti, G., 2015. Validation of Spatial Integrity Constraints in City Models, Proceedings of the Fourth ACM SIGSPATIAL International Workshop on Mobile Geographic Information Systems, pp. 7079.

Biljecki, F., Ledoux, H., Stoter, J., 2017. Generating 3D city models without elevation data. Comput. Environ. Urban Syst. 64, 1-18. doi:10.1016/j.compenvurbsys.2017.01.001

Biljecki, F., Stoter, J., Ledoux, H., Zlatanova, S., Çöltekin, A., 2015. Applications of 3D City Models: State of the Art Review. ISPRS Int. J. Geo-Inf. 4, 2842-2889. doi:10.3390/ijgi4042842

Carnie, R., Walker, R., Corke, P., 2006. Image processing algorithms for UAV "sense and avoid." IEEE International Conference on Robotics and Automation, pp. 2848-2853.

Casbeer, D.W., Beard, R.W., McLain, T.W., Li, S.-M., Mehra, R.K., 2005. Forest fire monitoring with multiple small UAVs, in: Proceedings of the American Control Conference, pp. 3530 3535 vol. 5.

Cavoukian, A., 2012. Privacy and Drones: Unmanned Aerial Vehicles. IPC.

Choi, C.H., Jang, H.J., Lim, S.G., Lim, H.C., Cho, S.H., Gaponov, I., 2016. Automatic wireless drone charging station creating essential environment for continuous drone operation,
International Conference on Control, Automation and Information Sciences. pp. 132-136.

Chowdhury, S., Emelogu, A., Marufuzzaman, M., Nurre, S.G., Bian, L., 2017. Drones for disaster response and relief operations: A continuous approximation model. Int. J. Prod. Econ. 188, 167-184.

Clothier, R.A., Greer, D.A., Greer, D.G., Mehta, A.M., 2015. Risk Perception and the Public Acceptance of Drones. Risk Anal. 35, 1167-1183. doi:10.1111/risa.12330

Colomina, I., Molina, P., 2014. Unmanned aerial systems for photogrammetry and remote sensing: A review. ISPRS J. Photogramm. Remote Sens. 92, 79-97. doi:10.1016/j.isprsjprs.2014.02.013

Coulton, P., Lindley, J., Sturdee, M., Stead, M., 2017. Design Fiction as World Building. Presented at the Research Through Design.

Dablanc, L., Diziain, D., Levifve, H., 2011. Urban freight consultations in the Paris region. Eur. Transp. Res. Rev. 3, 4757. doi:10.1007/s12544-011-0049-2

Efrat, A., Mitchell, J.S.B., Sankararaman, S., Myers, P., 2012. Efficient Algorithms for Pursuing Moving Evaders in Terrains, Proceedings of the 20th International Conference on Advances in Geographic Information Systems (ACM SIGSPATIAL), pp. $33-42$.

Fasano, G., Accardo, D., Tirri, A.E., Moccia, A., De, L., 2014. Morphological filtering and target tracking for vision-based UAS sense and avoid. International Conference on Unmanned Aircraft Systems, pp. 430-440.

Feng, D., Yuan, X., 2016. Automatic construction of aerial corridor for navigation of unmanned aircraft systems in class $G$ airspace using LiDAR. doi:10.1117/12.2224359

Fikar, C., Gronalt, M., Hirsch, P., 2016. A decision support system for coordinated disaster relief distribution. Expert Syst. Appl. 57, 104-116. doi:10.1016/j.eswa.2016.03.039

Finn, R.L., Wright, D., 2012. Unmanned aircraft systems: Surveillance, ethics and privacy in civil applications. Comput. Law Secur. Rev. 28, 184-194. doi:10.1016/j.clsr.2012.01.005

Gómez, C., Green, D.R., 2017. Small unmanned airborne systems to support oil and gas pipeline monitoring and mapping. Arab. J. Geosci. 10, 202. doi:10.1007/s12517-017$2989-x$

Gröger, G., Plümer, L., 2012. CityGML - Interoperable semantic 3D city models. ISPRS J. Photogramm. Remote Sens. 71, 12-33. doi:10.1016/j.isprsjprs.2012.04.004

Haidari, L.A., Brown, S.T., Ferguson, M., Bancroft, E., Spiker, M., Wilcox, A., Ambikapathi, R., Sampath, V., Connor, D.L., Lee, B.Y., 2016. The economic and operational value of using drones to transport vaccines. Vaccine 34, 4062-4067. doi:10.1016/j.vaccine.2016.06.022

Harrington, A., 2015. Who controls the drones? Eng. Technol. 10, 80-83. doi:10.1049/et.2015.0211 
Heutger, M., Kückelhaus, M., 2014. Unmanned Aerial Vehicle in Logistics: A DHL Perspective on implications and use cases for the logistics industry.

Itkin, M., Kim, M., Park, Y., 2016. Development of CloudBased UAV Monitoring and Management System. Sensors 16, 1913. doi: $10.3390 / \mathrm{s} 16111913$

Javier Irizarry, Dayana Bastos Costa, 2016. Exploratory Study of Potential Applications of Unmanned Aerial Systems for Construction Management Tasks. J. Manag. Eng. 32. doi:10.1061/(ASCE)ME.1943-5479.0000422

Jean-Marie Boussier, Tatiana Cucu, Luminita Ion, Dominique Breuil, 2011. Simulation of goods delivery process. Int. J. Phys. Distrib. Logist. Manag. 41, 913-930. doi:10.1108/09600031111175852

Jenkins, D., Vasigh, B., 2013. The Economic Impact of Unmanned Aircraft Systems Integration in the United States.

Jesse W.J. Weltevreden, 2008. B2c e-commerce logistics: the rise of collection-and-delivery points in The Netherlands. Int. J. Retail Distrib. Manag. 36, 638-660. doi:10.1108/09590550810883487

Jiang, L., Mahmassani, H., 2014. City Logistics. Transp. Res. Rec. J. Transp. Res. Board 2410, 85-95. doi:10.3141/2410-10

Kim, K., Kim, T., Lee, K., Kwon, S., 2011. Fuel cell system with sodium borohydride as hydrogen source for unmanned aerial vehicles. J. Power Sources, Fuel Cells Science \& Technology $2010 \quad$ 196, 9069-9075. doi:10.1016/j.jpowsour.2011.01.038

Kopardekar, P., Rios, J., Prevot, T., Johnson, M., Jung, J., III, J.E.R., 2016. UAS Traffic Management (UTM) Concept of Operations to Safely Enable Low Altitude Flight Operations, in: 16th AIAA Aviation Technology, Integration, and Operations Conference. American Institute of Aeronautics and Astronautics. doi:10.2514/6.2016-3292

Kunze, O., 2016. Replicators, Ground Drones and Crowd Logistics A Vision of Urban Logistics in the Year 2030. Transp. Res. Procedia, Transforming Urban Mobility. International Scientific Conference on Mobility and Transport. Conference Proceedings 19, 286-299. doi:10.1016/j.trpro.2016.12.088

Lai, J., Mejias, L., Ford, J.J., 2011. Airborne vision-based collision-detection system. J. Field Robot. 28, 137-157. doi:10.1002/rob.20359

Larsen, C., Paul, S., Svensson, A., Chowdhury, S., 2017. Optimizing Endurance and Stability of a Modular UAV Design: 55th AIAA Aerospace Sciences Meeting, doi:10.2514/6.20170244

Leonard, J., Savvaris, A., Tsourdos, A., 2012. Towards a fully autonomous swarm of unmanned aerial vehicles, in: Proceedings of 2012 UKACC International Conference on Control. pp. 286-291. doi:10.1109/CONTROL.2012.6334644

Lidynia, C., Philipsen, R., Ziefle, M., 2017. Droning on About Drones-Acceptance of and Perceived Barriers to Drones in Civil Usage Contexts, in: Advances in Human Factors in Robots and Unmanned Systems. Springer, pp. 317-329. doi:10.1007/978-3-319-41959-6_26
Lindholm, M., 2013. Urban freight transport from a local authority perspective - a literature review.

Luppicini, R., So, A., 2016. A technoethical review of commercial drone use in the context of governance, ethics, and privacy. Technol. Soc. 46, 109-119. doi:10.1016/j.techsoc.2016.03.003

Moosbrugger, P., Rozier, K.Y., Schumann, J., 2017. R2U2: monitoring and diagnosis of security threats for unmanned aerial systems. Form. Methods Syst. Des. 51, 31-61. doi:10.1007/s10703-017-0275-x

Muñoz, F., Espinoza, E.S., Gonzalez, I., Carrillo, L.R.G., Salazar, S., Lozano, R., 2015. A UAS obstacle avoidance strategy based on spiral trajectory tracking, in: International Conference on Unmanned Aircraft Systems (ICUAS)., pp. 593600.

Murray, C.C., Chu, A.G., 2015. The flying sidekick traveling salesman problem: Optimization of drone-assisted parcel delivery. Transp. Res. Part C Emerg. Technol. 54, 86-109. doi:10.1016/j.trc.2015.03.005

Nha, V.T.N., Djahel, S., Murphy, J., 2012. A comparative study of vehicles' routing algorithms for route planning in smart cities, in: First International Workshop on Vehicular Traffic Management for Smart Cities (VTM)., pp. 1-6. doi:10.1109/VTM.2012.6398701

Ni, J., Yao, L., Zhang, J., Cao, W., Zhu, Y., Tai, X., 2017. Development of an Unmanned Aerial Vehicle-Borne CropGrowth Monitoring System. Sensors 17, 502. doi:10.3390/s17030502

Oliver, J.M., 2017. Current Status of the Use of Small Unmanned Aerial Systems for Environmental Monitoring. Environ. Claims J. 29, 159-170. doi:10.1080/10406026.2017.1307009

Percivall, G.S., Reichardt, M., Taylor, T., 2015. Common Approach to Geoprocessing of UAV Data Across Application Domains, in: ISPRS - International Archives of the Photogrammetry, Remote Sensing and Spatial Information Sciences. pp. 275-279. doi:10.5194/isprsarchives-XL-1-W4275-2015

Pestana, J., Sanchez-Lopez, J.L., Campoy, P., Saripalli, S., 2013. Vision based GPS-denied Object Tracking and following for unmanned aerial vehicles, in: IEEE International Symposium on Safety, Security, and Rescue Robotics (SSRR). pp. 1-6. doi:10.1109/SSRR.2013.6719359

Prats, X., Delgado, L., Ramírez, J., Royo, P., Pastor, E., 2012. Requirements, Issues, and Challenges for Sense and Avoid in Unmanned Aircraft Systems. J. Aircr. 49, 677-687. doi:10.2514/1.C031606

Procedia, 19th EURO Working Group on Transportation Meeting, EWGT2016, 5-7 September 2016, Istanbul, Turkey 22, 588-597. doi:10.1016/j.trpro.2017.03.048

Quiroz, G., Kim, S.J., 2017. A Confetti Drone: Exploring drone entertainment, in: 2017 IEEE International Conference on Consumer Electronics (ICCE)., pp. 378-381. doi:10.1109/ICCE.2017.7889362 
Sanchez-Lopez, J.L., Molina, M., Bavle, H., Sampedro, C., Fernández, R.A.S., Campoy, P., 2017. A Multi-Layered Component-Based Approach for the Development of Aerial Robotic Systems: The Aerostack Framework. J. Intell. Robot. Syst. 1-27. doi:10.1007/s10846-017-0551-4

Schneider, D., 2017. Air traffic control for delivery drones [Top Tech 2017]. IEEE Spectr. 54, 32-33. doi:10.1109/MSPEC.2017.7802742

Schumann, J., Rozier, K., Reinbacher, T., Mengshoel, O., Mbaya, T., Ippolito, C., 2013. Towards Real-time, On-board, Hardware-supported Sensor and Software Health Management for Unmanned Aerial Systems. Annu. Conf. Progn. Health Manag. Soc.

Shepard, D.P., Humphreys, T.E., Fansler, A.A., 2012. Evaluation of the vulnerability of phasor measurement units to GPS spoofing attacks. Int. J. Crit. Infrastruct. Prot. 5, 146-153. doi:10.1016/j.ijcip.2012.09.003

Shively, R.J., 2014. Breaking Down Barriers to UAS Integration: What are government agencies doing? Proc. Hum. Factors Ergon. Soc. Annu. Meet. 58, 41-43. doi:10.1177/1541931214581009

Siedschlag, A., Alperen, M.J., 2017. Ethical, Legal, and Social Issues in Homeland Security - What They Are and How to Address Them, in: Foundations of Homeland Security. John Wiley \& Sons, Inc., pp. 29-54. doi:10.1002/9781119289142.ch3

Smolyanskiy, N., Kamenev, A., Smith, J., Birchfield, S., 2017. Toward Low-Flying Autonomous MAV Trail Navigation using Deep Neural Networks for Environmental Awareness. ArXiv170502550 Cs.

Steele, R.D., 2017. Unhinged: drone assassination - American suicide. Intell. Natl. Secur. 0, 1-6. doi:10.1080/02684527.2017.1296659

Tahboub, R.Y., Rompf, T., 2016. On Supporting Compilation in Spatial Query Engines: (Vision Paper), in: Proceedings of the 24th ACM SIGSPATIAL International Conference on Advances in Geographic Information Systems, doi: $10.1145 / 2996913.2996945$

Vattapparamban, E., Güvenç, İ., Yurekli, A.İ., Akkaya, K., Uluağaç, S., 2016. Drones for smart cities: Issues in cybersecurity, privacy, and public safety, in: International Wireless Communications and Mobile Computing Conference (IWCMC)., pp. 216-221. doi:10.1109/IWCMC.2016.7577060

Wang, C.-Y., Xu, T., Ge, S., Zhang, G., Yang, X.-G., Ji, Y., 2016. A Fast Rechargeable Lithium-Ion Battery at Subfreezing Temperatures. J. Electrochem. Soc. 163, A1944-A1950. doi:10.1149/2.0681609jes

Yang, A., Fan, H., Jing, N., 2016. Amateur or Professional: Assessing the Expertise of Major Contributors in OpenStreetMap Based on Contributing Behaviors. ISPRS Int. J. Geo-Inf. 5, 21. doi:10.3390/ijgi5020021

Zabihi, S.M., Beauchemin, S.S., Medeiros, E.A.M.D., Bauer, M.A., 2015. Lane-based vehicle localization in urban environments, in: 2015 IEEE International Conference on Vehicular Electronics and Safety (ICVES). pp. 225-230.
Zissis, D., Aktas, E., Bourlakis, M., 2017. A New Process Model for Urban Transport of Food in the UK. Transp. Res. 